\title{
Speaking style adaptations across the lifespan
}

\section{Elisa Ferracane ${ }^{1}$, Cristabella Trimble-Quiz¹ ${ }^{1}$ Karen Johnson², Rachael Gilbert¹, Rajka Smiljanic ${ }^{1}$}

\section{${ }^{1}$ Department of Linguistics, ${ }^{2}$ Department of Communication Sciences \& Disorders, The University of Texas at Austin}

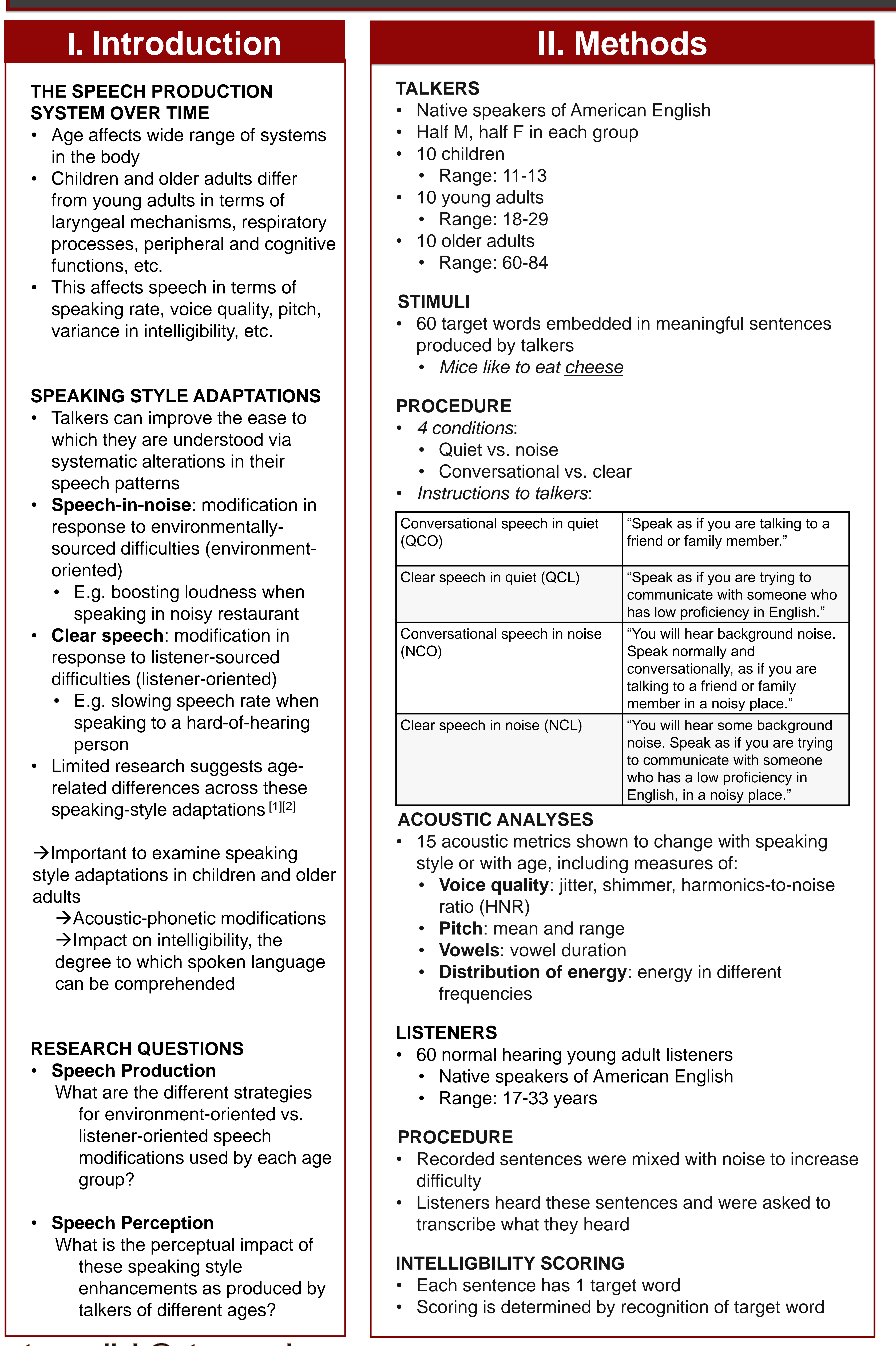

utsoundlab@utexas.edu

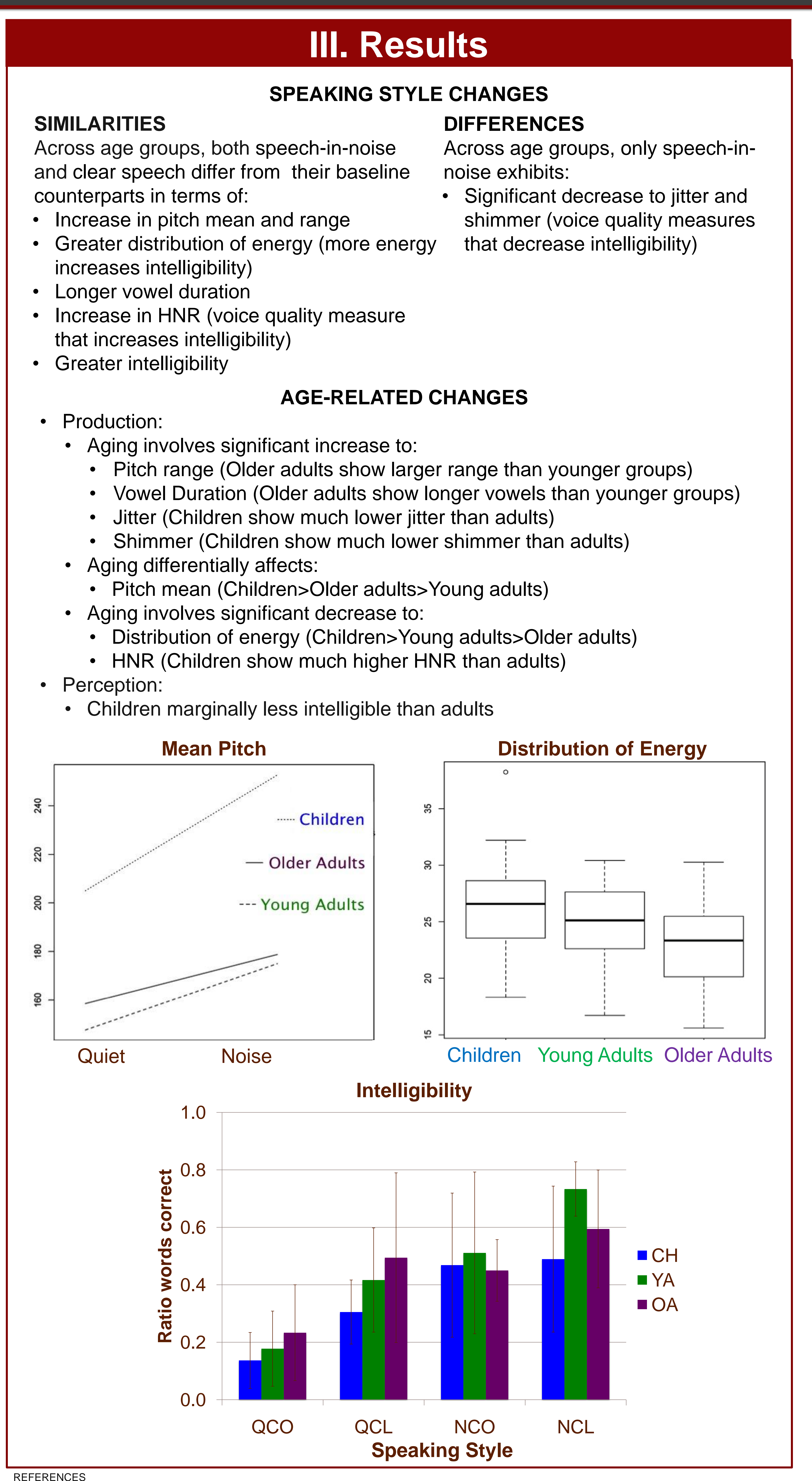

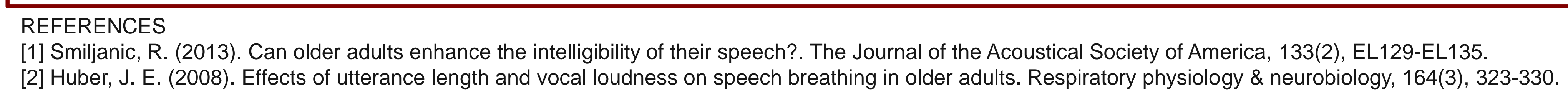

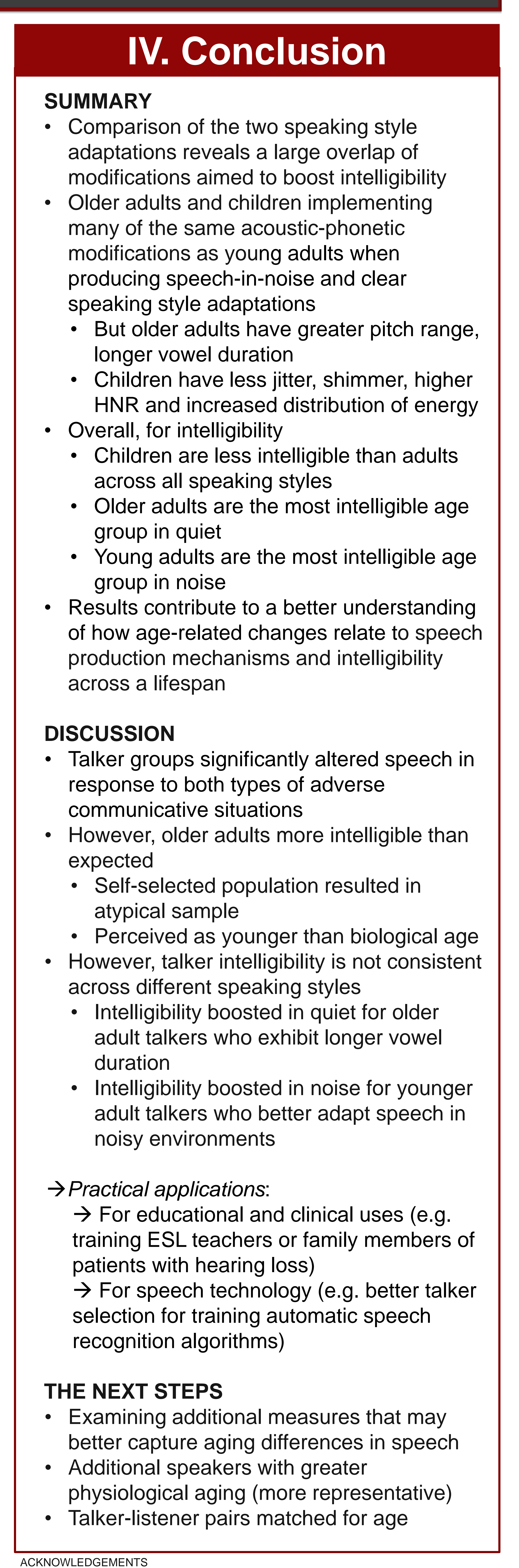

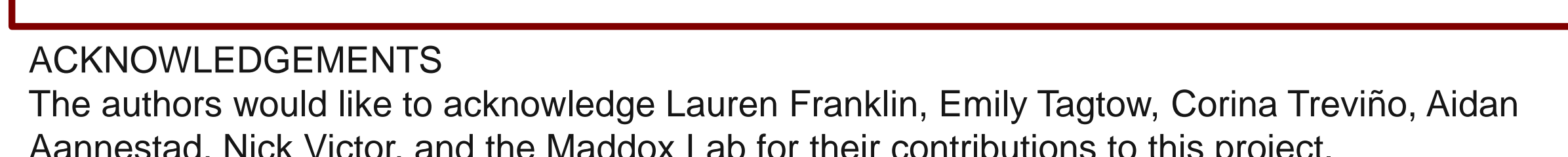

